\title{
Thermal Stability and Lubrication Properties of Biodegradable Castor Oil on AISI 4140 Steel
}

\author{
María Teresa Hernández-Sierra ${ }^{1}$ (D), Luis Daniel Aguilera-Camacho ${ }^{1}$, José Eduardo Báez-García ${ }^{2}$, \\ J. Santos García-Miranda ${ }^{1}$ and Karla J. Moreno ${ }^{1, *(1)}$ \\ 1 Tecnológico Nacional de México/Instituto Tecnológico de Celaya, Apartado Postal 57, Celaya 38010, Mexico; \\ tere.mths@hotmail.com (M.T.H.-S.); daniel.aguilera@itcelaya.edu.mx (L.D.A.-C.); \\ santos.garcia@itcelaya.edu.mx (J.S.G.-M.) \\ 2 Facultad de Química, Universidad de Guanajuato, Noria Alta S/N, Guanajuato 36050, Mexico; \\ jebaez14@yahoo.com.mx \\ * Correspondence: karla.moreno@itcelaya.edu.mx; Tel.: +52-461-6117575; Fax: +52-461-6117878
}

Received: 9 May 2018; Accepted: 2 June 2018; Published: 6 June 2018

\begin{abstract}
Lubricants have much importance in several industries, principally serving to reduce friction and wear in mechanical elements. In this study, the influence of Castor oil as bio-lubricant on the friction and wear performance of AISI 4140 steel was investigated. For that purpose, pin-on-disk friction tests were conducted according to ASTM G-99, by using pins of tungsten carbide (WC) as counterparts. The experiments were performed at two different temperatures. This work also presents the Attenuated Total Reflection Fourier Transform Infrared Spectroscopy (ATR-FTIR) and ${ }^{1} \mathrm{H}-\mathrm{NMR}$ analyses for the chemical characterization of oils and a study of their degradation by oxidation. The analysis of the damage caused to steel due to friction was deepened by analyzing its microhardness and microstructure in the worn zone. As a reference, the same experiments were performed with a commercial oil. The friction behavior of 4140 steel/WC with Castor oil lubrication at the two temperatures was notably better than that obtained under the reference oil lubrication. The kinetic friction coefficient $\left(\mu_{\mathrm{k}}\right)$ was up to $76 \%$ lower. However, a slight increase in steel wear was observed under Castor oil lubrication. Despite this, these results suggest that Castor oil could be used as bio-lubricant in systems which are susceptible to levels of high friction.
\end{abstract}

Keywords: AISI 4140 steel; sliding friction; bio-lubricant; Castor oil; microhardness; microstructural change; FTIR; ${ }^{1} \mathrm{H}-\mathrm{NMR}$

\section{Introduction}

Lubricants play a major role in several industries around the world, mainly because they reduce friction and wear on mechanical elements [1]. Nowadays, commercial lubricants have changed significantly, with the aim of reducing the environmental damage that process technologies and products cause to our planet, as well as fulfilling the expectations, needs, and demands of the public, the market, and governmental regulations [2-4]. For that reason, there is a growing interest in the use of biodegradable lubricants which are friendly to the environment, renewable, less toxic, and possess superior tribological properties [2-4]. In addition to their biodegradability and low toxicity, they have excellent lubricity performance, adhere to metal surfaces with ease, possess little volatility and slight viscosity dependence with temperature. Although they have low oxidation stability and flow properties at low temperatures [4], several studies had been realized to propose the use of vegetable oils as substitutes for commercial mineral or synthetic oils, either pure, with the inclusion of some additives, or even chemically modified. 
Castor oil is a non-edible vegetable oil obtained from the seed of the Ricinus communis L. plant which is cultivated principally in India, Africa, and South America [5]. Castor oil has high hydroxyl value, viscosity, and density that make it be distinguished from other oils [5-7]. Castor oil is widely used in different industries, and the number of its applications continues to grow; some of them are the cosmetic, pharmaceutical, paint, fuel, biopolymer fields, among others [5,6]. In addition to these applications, Madankar et al. [8] suggested that Castor oil is a promising bio-lubricant thanks to its good lubricity properties, high viscosity, low pour point, and the low cost of production. In fact, its use has been reported as a bio-lubricant in different studies of its tribological behavior; by comparing it with commercial oils, Castor oil showed significant lubricating effects [5,8,9]. Recently, our research group reported an improvement on the tribological behavior of hardened AISI 4140 steel by using castor oil as bio-lubricant, observing low friction coefficients of up to 0.035 , and wear rate values of $1.02 \times 10^{-8} \mathrm{~mm}^{3} / \mathrm{Nm}$ in a system of $4140 / \mathrm{Al}_{2} \mathrm{O}_{3}$ at room temperature [9]. Zeng and Dong [10] found promising friction results in a tribosystem of Nitinol 60 alloy pin and GCr15 steel under lubrication with Castor oil. Meanwhile, Jain and Suhane [7], studied the tribological characteristics of a tribosystem consisting of a pin of plain carbon steel and disks of mild steel (under different loads and speeds). By using Castor oil as a lubricant, they recorded friction coefficients from 0.015 to 0.026 .

AISI 4140 steel is one of the main substrate materials for abrasive and adhesive wear applications, and it is used extensively in industrial mechanical elements thanks to its high hardness and toughness properties $[9,11]$. In this work, the influence of Castor oil on AISI 4140 steel was evaluated. For this study, friction and wear tests of AISI 4140 steel against tungsten carbide (WC) were performed at two different temperatures $\left(25\right.$ and $\left.70{ }^{\circ} \mathrm{C}\right)$ by employing Castor oil as a lubricant. In order to assess how near or far pure Castor oil (without additives) is from commercial oils, the same experiments were done with a reference oil. Additionally, extensive characterization of the molecular structures of lubricants by ATR-FTIR and ${ }^{1} \mathrm{H}-\mathrm{NMR}$ techniques, as well as the evaluation of viscosity with temperature were addressed.

\section{Materials and Methods}

\subsection{Lubricants}

In this work, two oils were employed for the experiments. One of them was biodegradable Castor oil that was obtained by the method described in Section 2.2. The other was a commercial oil which, according to the supplier's information, consists of mineral oil of a certain fraction, chlorinated paraffins, anti-corrosion additives, and synthetic high-pressure additives (named Reference oil in this work). This Reference oil is used in manufacturing processes as a lubricant for mechanical elements that work under contact pressure values of around $1000 \mathrm{MPa}$. Table 1 lists some properties of the oils. It can be seen that the viscosity index (VI) of Castor oil is higher than that of the Reference oil; this means that it has lower variation of viscosity with temperature. Furthermore, Castor oil exhibits a higher Flash point and lower Pour point, which allow it to be used over a wider range of temperatures.

Table 1. Characteristics and properties of oils.

\begin{tabular}{ccc}
\hline Characteristic & Castor Oil & Reference Oil \\
\hline Density at $25^{\circ} \mathrm{C}\left(\mathrm{kg} / \mathrm{m}^{3}\right)^{\mathrm{a}}$ & 880 & 1030 \\
Density at $70^{\circ} \mathrm{C}\left(\mathrm{kg} / \mathrm{m}^{3}\right)^{\mathrm{a}}$ & 850 & 1000 \\
Viscosity at $40^{\circ} \mathrm{C}\left(\mathrm{mm}^{2} / \mathrm{s}\right)^{\text {a }}$ & 173 & 277 \\
Viscosity at $100^{\circ} \mathrm{C}\left(\mathrm{mm}^{2} / \mathrm{s}\right)^{\mathrm{a}}$ & 15 & 17 \\
Viscosity Index $(\mathrm{VI})^{\mathrm{a}}$ & 84 & 49 \\
Flash point $\left({ }^{\circ} \mathrm{C}\right)$ & $200^{\mathrm{b}}$ & $180^{\mathrm{c}}$ \\
Pour point $\left({ }^{\circ} \mathrm{C}\right)$ & $-27^{\mathrm{b}}$ & $-10^{\mathrm{c}}$ \\
\hline
\end{tabular}

a Values measured by authors. ${ }^{b}$ Typical values from the literature. ${ }^{c}$ Values from supplier information. 


\subsection{Castor Oil Extraction}

Castor oil was extracted from Mexican Ricinus seeds through chemical extraction by employing $n$-hexane in a Soxhlet apparatus. The extraction time was $4 \mathrm{~h}$ per sample. In order to recover the hexane from the hexane-oil mixture obtained, once the extraction was complete, the hexane was separated through evaporation by using a rotary evaporator.

\subsection{Characterization of Lubricants}

\subsubsection{Chemical Characterization}

In our chemical characterization of the oils, two techniques were employed: Attenuated Total Reflection Fourier Transform Infrared Spectroscopy (ATR-FTIR) and Nuclear Magnetic Resonance ( $\left.{ }^{1} \mathrm{H}-\mathrm{NMR}\right)$. FTIR spectra of the oil samples were acquired on a Spectrum 100 Perkin Elmer spectrometer (Perkin Elmer, Mexico) equipped with a detector of LiTa03 and beam splitter of KBr, and coupled with an attenuated total reflectance infrared sensor of ZnSe. Samples were scanned in the range of $600-4000 \mathrm{~cm}^{-1}$ wavenumbers with a resolution of $4.0 \mathrm{~cm}^{-1}$ and four scans. Before each spectrum scanning, the ATR plate was carefully cleaned with hexane and a soft tissue, twice followed by ethanol and dried in air; then, an air background spectrum was performed. Finally, a few drops of the entire sample were placed on the ATR plate to make the scans. The results, adjusted to a baseline, are shown in infrared spectrums of transmittance as a function of wavenumber. The ${ }^{1} \mathrm{H}-\mathrm{NMR}$ spectra were recorded at room temperature on a Bruker 500 Ultrashield Plus spectrometer (Bruker, Mexico). Oil samples were diluted in Chloroform-d $\left(\mathrm{CDCl}_{3}\right)$, and all spectra were referenced to the residual solvent $\mathrm{CDCl}_{3}\left(\delta(\mathrm{ppm}) 7.26\left({ }^{1} \mathrm{H}\right)\right)$.

\subsubsection{Viscosity Measurements}

Viscosity is an essential parameter in lubrication that varies with temperature, pressure, and shear rate; ideally, the higher the viscosity, the better performance. That could happen because the film would be thicker and would provide major separation of the surfaces in contact [12]. To know the variation of viscosity with respect to temperature, viscosity measurements of Castor and Reference oil at temperatures from 25 to $80{ }^{\circ} \mathrm{C}$ were performed. For this purpose, a DV-II+ Pro Brookfield Viscometer equipped with a Brookfield Thermosel system and S21 spindle were employed (Brookfield AMETEK, Middleborough, MA, USA). The lubricant was placed into the chamber ( $8 \mathrm{~mL})$, the sample was heated to the desired constant temperature, and the readings were taken. Viscosity measurements were performed at shear rates from 18.6 to $186 \mathrm{~s}^{-1}$, in order to have an acceptable torque percentage, i.e., between 10 and 100, and be considered a correct measurement. Five measurements were taken for each temperature and oil to ensure repeatability.

\subsection{Tribological Assessment}

For this study, disks of AISI 4140 steel of $5 \mathrm{~mm}$ of thickness and $25.4 \mathrm{~mm}$ diameter were obtained from a commercial AISI 4140 annealed steel bar. The chemical composition of the steel [9] is: $\mathrm{Cr}$ (1.04 wt \%), Mn (0.96 wt \%), C (0.43 wt \%), Si (0.18 wt \%), Mo (0.16 wt \%), S (0.04 wt \%), P (0.03 wt \%), and Fe (balance). The optical micrograph in Figure 1 confirmed the steel condition, showing that the microstructure consists of ferrite and coarse pearlite phases. The disks were polished under a wet grinding process until an average roughness of $0.04 \mu \mathrm{m}$ in Ra was achieved to compare all the tests under the same initial conditions. The roughness of the surfaces was measured using a contact profilometer Mitutoyo SJ-400 (Mitutoyo, Mexico). Commercial balls of $6 \mathrm{~mm}$ in diameter of tungsten carbide $(\mathrm{Ra}=0.03 \mu \mathrm{m})$ were employed as pin specimens.

Pin-on-disk wear tests were conducted in a CSM Instruments tribometer (CSM Instruments, Needham, MA, USA), according to the Standard Test Method for Wear Testing (ASTM G99-05) in lubricated conditions at 25 and $70{ }^{\circ} \mathrm{C}$. All experiments were performed with a wear track radius of $2 \mathrm{~mm}$, linear speed of $0.025 \mathrm{~m} / \mathrm{s}$, sliding distance of $1000 \mathrm{~m}$, and a contact pressure of $978 \mathrm{MPa}$. 
The duration of each test at these conditions was $11.11 \mathrm{~h}$. According to the liquid cup configuration, the samples were completely immersed in 25 and $60 \mathrm{~mL}$ of lubricant for tests at 25 and $70{ }^{\circ} \mathrm{C}$, respectively. Friction tests were carried out five times to ensure repeatability of results, and the averages are presented. In accordance with the above conditions, as well as the properties of the oils, this tribosystem worked under a boundary lubrication regime, as calculated in Appendix A, for the two lubricants and temperatures.

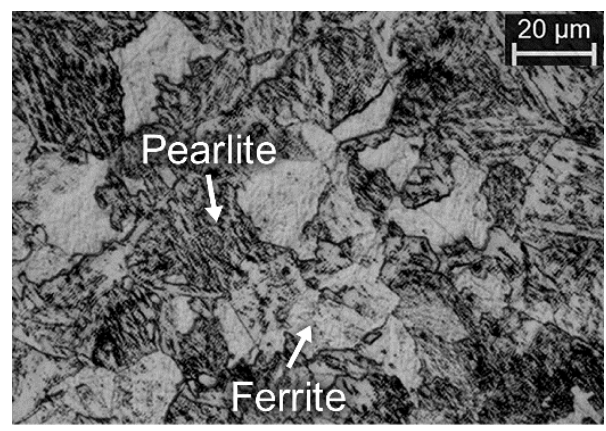

Figure 1. Optical micrograph of the AISI 4140 steel microstructure consisting of ferrite and pearlite constituents.

Immediately before testing and measuring, the disk and pin surfaces were cleaned with hexane to identify the existing wear. The kinetic friction coefficient $\left(\mu_{\mathrm{k}}\right)$ was recorded during the experiments using the equipment's software (Tribox 4.5.R, CSM Instruments, Needham, MA, USA). The wear tracks' widths and mechanisms were observed and determined by a Carl Zeiss Axio Imager.A1m microscope (ZEISS, Mexico). The wear was determined from the wear scar on the steel disk, since the pin did not suffer significant wear. Wear measurements were reported as volume loss (V) and wear rate $(K)$, which were calculated from Equations (1) and (2). In Equation (1), R represents the wear track radius, $d$ the wear track width, and $r$ the pin radius. In Equation (2), $F$ is the normal load, and $S$ the sliding distance.

$$
\begin{gathered}
\mathrm{V}=\pi \mathrm{Rd}^{3} / 6 \mathrm{r} \\
\mathrm{K}=\mathrm{V} / \mathrm{FS}
\end{gathered}
$$

With the aim of studying the effects of a friction process on the hardness of the material, Vickers microhardness on the wear track surfaces of the 4140 steel disks was measured with a Microindenter Vicker Knoop Auto SMVK-1000ZS (Metrotec, Spain) with a load of $9.8 \mathrm{~N}$ for $15 \mathrm{~s}$.

\subsection{Lubricant Degradation}

Oxidation is an important reaction to lubricant, affecting its lubrication performance; it is responsible for several problems, such as an increase in viscosity and acidification, and additive depletion, among others. This phenomenon occurs when a lubricant oil is exposed to elevated temperatures, pressures, and oxygen from the air. The oil's hydrocarbons react with oxygen and form various compounds such as esters, ketones, aldehydes, and carbonated and carboxylic acids, the majority of which present signals within the carbonyl group $(C=O)[13,14]$. At this point, Fourier transform infrared spectroscopy (FTIR) is a technique which is well known for its exceptional ability to qualitatively and quantitatively analyize chemical compounds [15]. Based on ASTM E 2412-04, ASTM E 168-99, and Macián et al. [13], this technique was used to evaluate the oxidation of oils which occurred during their use as lubricants in friction tests. The equipment used for this characterization was described in Section 2.3.1. For that purpose, a representative aliquot was taken from each oil before and after friction tests, it was diluted in $n$-hexane $(5: 100 \mathrm{v} / \mathrm{v})$ and carefully introduced into a $\mathrm{CaF}_{2}$ sealed cell (pathlength of $0.5 \mathrm{~mm}$ ) by a syringe to avoid partial filling or air bubbles entering the cell. An air background spectrum was run before each measurement. Then, a certain amount of hexane, 
followed by ethanol and air were passed through the cell to clean it before the next sample analysis. The results were adjusted for baseline and corrected to the reference pathlength of $0.1 \mathrm{~mm}$ before measurements were recorded. The analysis was made by calculating the area of the spectral band to be around $1743 \mathrm{~cm}^{-1}$ in absorbance, measured from 1770 to $1650 \mathrm{~cm}^{-1}$, and by using a baseline from 1850 to $1620 \mathrm{~cm}^{-1}$.

\section{Results and Discussion}

\subsection{Characterization of Lubricants}

\subsubsection{Chemical Characterization}

Castor oil is a triglyceride and consists principally of esters of ricinoleic fatty acid [5,16]. On the other hand, the commercial oil employed in this investigation as a reference is a fully-formulated oil that consists mainly of mineral base stock, chlorinated paraffins, and additives. On that point, mineral oils have a very complex composition; their chemical structures are composed of many aliphatic (straight) and cyclic carbon chains bonded together [12]. Chlorinated paraffins are complex mixtures of polychlorinated n-alkanes. Figure 2 shows the FTIR spectra of Castor (a) and Reference (b) oil; each signal on the image shows its corresponding functional group. In the Castor oil spectrum (Figure 2a), the presented peaks coincide with those of reference spectrums for Castor Oil [16]. One of the most important signals that distinguish it from others vegetable oils is the broad peak at $3406 \mathrm{~cm}^{-1}$ that corresponds to the hydroxyl group (O-H) of the ricinoleic fatty acid. With regard to the Reference oil spectrum, it is important to highlight the moderate peak at $662 \mathrm{~cm}^{-1}$, which is characteristic of the $\mathrm{C}-\mathrm{Cl}$ stretching vibration that confirmed the presence of chlorinated paraffin [12,17].
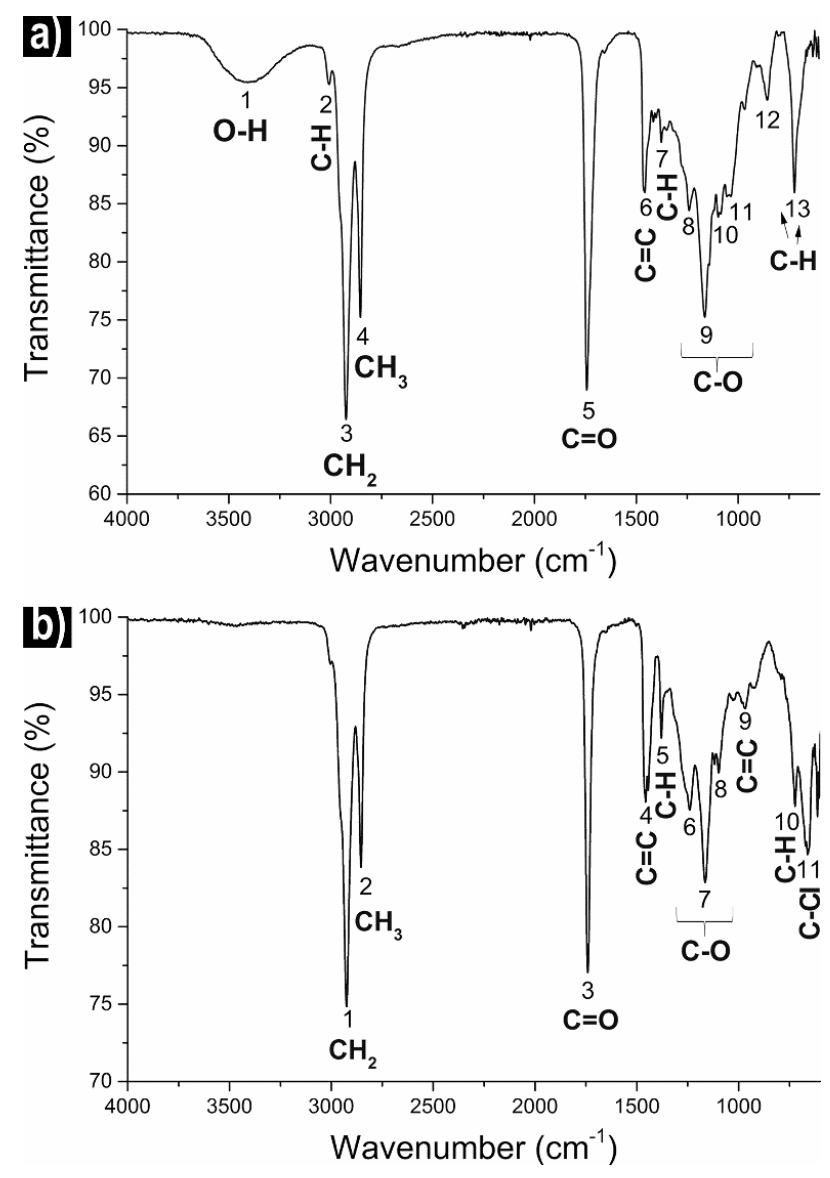

Figure 2. FTIR spectra of Castor (a) and Reference (b) oil. 
The ${ }^{1} \mathrm{H}-\mathrm{NMR}$ technique was used for the structure elucidation of the oils. Figure 3 shows the ${ }^{1}$ H-NMR spectra of Castor (a) and Reference (b) oil, as well as the generic molecules of which they consist. The general assignment of the signals of these spectra is well documented. The Castor oil spectrum (Figure 3a) shows pure signals due to the protons of the triacylglycerol of ricinoleic acid presented in the oil. It had been suggested that natural oils present flexible ester groups and a high degree of linearity [18]. On that point, Hamrock et al. [19] have been reported that straight chain molecules like polar and paraffinic molecules can be packed efficiently on a surface, which is a desirable feature in a boundary lubricant. This is characteristic of the chemical adsorption mechanism of boundary lubrication.

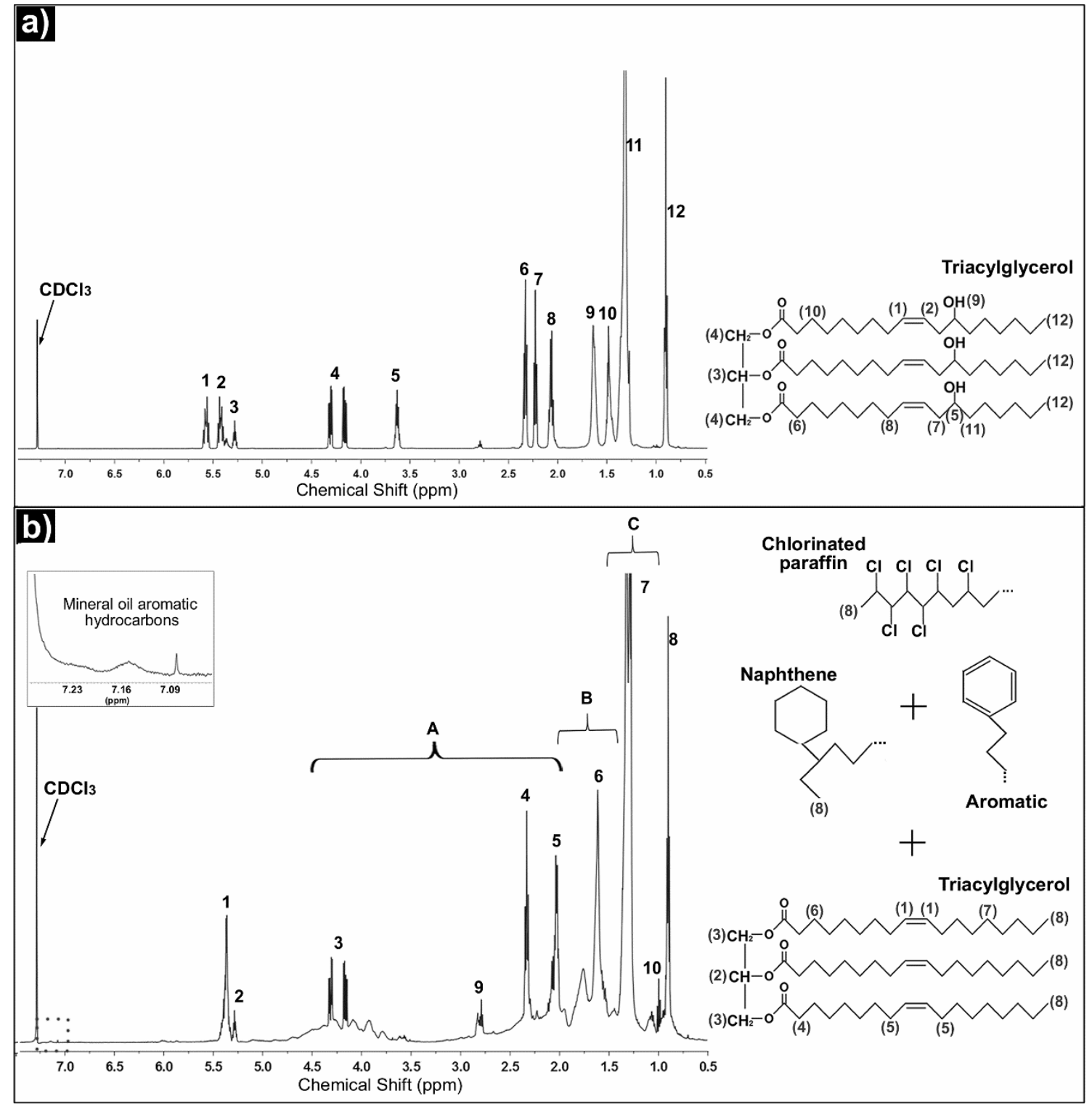

Figure 3. ${ }^{1} \mathrm{H}-\mathrm{NMR}$ spectra of Castor (a) and Reference (b) oil in $\mathrm{CDCl}_{3}$ at $500 \mathrm{MHz}$.

On the other hand, the Reference oil, as previously mentioned, presented several overlapping spectral signals due to protons of different natures. For instance, the signals numbered from 1 to 10 represent the protons of a triacylglycerol structure which, as can be seen, consists mostly of oleic fatty acid. However, it also presented broader and smaller signals (assigned regions from A to C), characteristic of the multi-mixture character of mineral oils [20]. The composition of mineral oil is 
very complicated; they have molecules of a great number of possible forms, and so, it is not possible to give a precise analysis of mineral oil. The elemental chemical forms are paraffinic, naphthenic, and aromatic. As can be identified from inset in Figure 3b, aromatics hydrocarbons are present only as minor components, while mineral oil saturated hydrocarbons, paraffinic, and naphthenic are the principal mineral components in the oil. The corresponding signals at region A correspond to paraffinic and naphthenic hydrogens $\mathrm{CH}, \mathrm{CH}$, and $\mathrm{CH}$, region $\mathrm{B}$ to naphthenic hydrogens $\mathrm{CH} 2$, and $\mathrm{C}$ to paraffinic hydrogens $\mathrm{CH} 2$ and $\mathrm{CH} 3$ groups $[20,21]$. These results suggest that Reference oil is a hybrid oil that possess a complex molecular structure, with mineral components and a fraction of fatty acids in a triacylglycerol structure.

\subsubsection{Viscosity Measurements}

The variation of viscosity with temperature will also affect the friction and wear performance of any lubricant. Generally, a minor change in viscosity with temperature is desirable for lubricants to work effectively in a wider range of temperature conditions. The Arrhenius-type equation $\eta=A \cdot \exp (\mathrm{Ea} / \mathrm{R} \cdot \mathrm{T})$, was used to describe the exponential decrease of the viscosity with temperature of the lubricants. In this equation, $\eta$ is the dynamic viscosity, $\mathrm{A}(\mathrm{Pa} \cdot \mathrm{s})$ the pre-exponential factor, Ea $\left(\mathrm{J} \cdot \mathrm{mol}^{-1}\right)$ is the flow activation energy, $\mathrm{R}\left(8.3145 \mathrm{~J} \cdot \mathrm{mol}^{-1} \cdot \mathrm{K}^{-1}\right)$ the universal gas constant, and $\mathrm{T}$ (K) the absolute temperature. Figure 4 shows the variation of viscosity with temperature and the Arrhenius fittings of Castor and Reference Oil, whereas Table 2 lists the results of these regressions. It can be seen that the dynamic viscosity of both oils decreases with temperature, as expected, from 25 to $80{ }^{\circ} \mathrm{C}(298.15$ to $353.15 \mathrm{~K})$. There is a significant difference in the viscosities of the oils at $25^{\circ} \mathrm{C}$ ( $298.15 \mathrm{~K})$, being higher for Reference oil. However, at high temperatures, the dynamic viscosity of the samples became very similar.

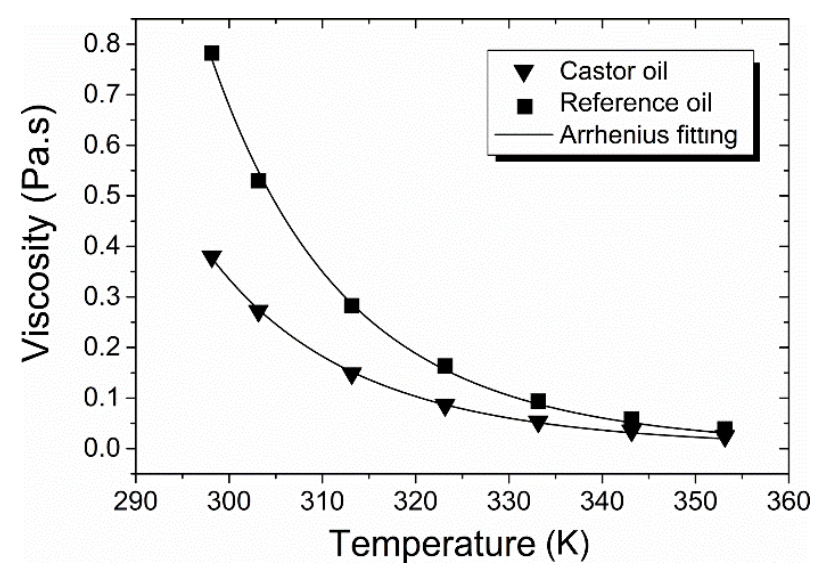

Figure 4. Variation of viscosity with temperature and Arrhenius fittings of Castor and Reference oil.

Table 2. Results of nonlinear Arrhenius regressions.

\begin{tabular}{cccccc}
\hline \multirow{2}{*}{ Lubricant } & \multicolumn{2}{c}{$\mathbf{A}(\mathbf{P a} \cdot \mathbf{s})$} & \multicolumn{2}{c}{ Ea $\left(\mathbf{k J} \cdot \mathbf{m o l}{ }^{-\mathbf{1}}\right)$} & \multirow{2}{*}{$\mathbf{R}^{\mathbf{2}}$} \\
\cline { 2 - 5 } & Value & Standard Error & Value & Standard Error & \\
\hline Castor oil & $2.18 \times 10^{-9}$ & $7.13 \times 10^{-10}$ & 47.0 & 0.78 & 1 \\
Reference oil & $8.28 \times 10^{-10}$ & $4.41 \times 10^{-10}$ & 51.2 & 1.27 & 1 \\
\hline
\end{tabular}

\subsection{Tribological Behavior}

Figure 5 shows the evolution of the friction coefficient $\left(\mu_{\mathrm{k}}\right)$ with sliding distance of AISI 4140 steel against tungsten carbide (WC) at $25^{\circ} \mathrm{C}$ (Figure 5a) and $70{ }^{\circ} \mathrm{C}$ (Figure 5b) by employing Castor and Reference oil as lubricants. At $25^{\circ} \mathrm{C}$, both friction coefficients exhibited a tendency to decrease when 
sliding distance increases, while at $70{ }^{\circ} \mathrm{C}$, a slight fluctuation on friction coefficient was observed for the two lubricants, and had no clear trend to increase or decrease with sliding distance. The lowest friction coefficients were obtained with the use of Castor oil as lubricant at two temperatures, $\mu_{\mathrm{k}}=0.068$ and $\mu_{\mathrm{k}}=0.023$ at 25 and $70{ }^{\circ} \mathrm{C}$ respectively, which were $27 \%$ and $76 \%$ lower than those with Reference oil lubrication at 25 and $70{ }^{\circ} \mathrm{C}$. As mentioned before, the mechanism of boundary lubrication given by linear molecules can be more effective than ring or cross-linked molecules, such as those present in the Reference oil. Thus, the linear molecules present in the Castor oil could be promoting the observed low friction coefficients.

On the other hand, it can be noticed that under lubrication with Castor oil, the friction coefficient tends to decrease when temperature increases; this was also observed by Zhang et al. [18] with other lubricants. In fact, it has been reported that many organic lubricants form a protective layer at higher temperatures by thermal activation. This has been attributed to the formation of a soap on the metal surfaces [19].
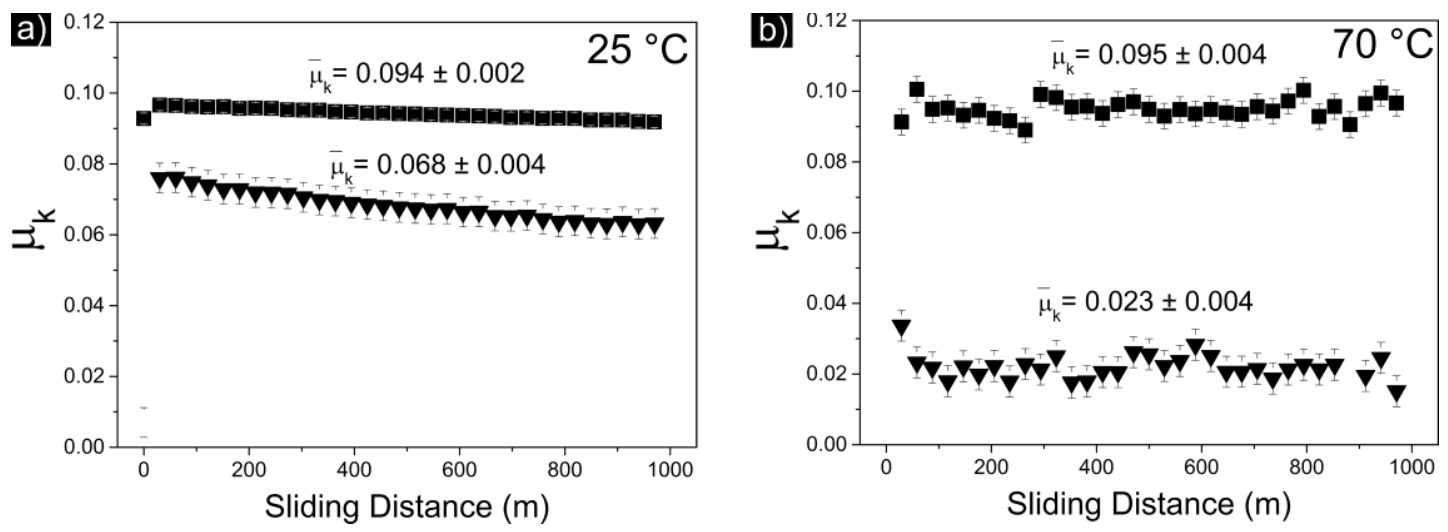

Figure 5. Kinetic friction coefficient $\left(\mu_{\mathrm{k}}\right)$ evolution vs. sliding distance of AISI 4140 -WC by using Castor $(\boldsymbol{\nabla})$ and Reference $(\boldsymbol{\square})$ oil at $(\mathbf{a}) 25^{\circ} \mathrm{C}$ and (b) $70^{\circ} \mathrm{C}$.

Micrographs and wear track profiles of the wear surface of 4140 steel disks after friction tests are shown in Figure 6. In this figure, it can be seen that at $25^{\circ} \mathrm{C}$, with both lubricants, wear is very low. The surface texture of the samples lubricated with Castor oil changed (burnishing), and some furrows can be notices. In contrast, on the samples lubricated with Reference oil, scarcely polishing on the wear surface can be noticed, as well as some plastic deformation. As seen in the wear track profiles, pile up was observed on both samples. However, at $70^{\circ} \mathrm{C}$, the wear scar width and magnitude of damage increased significantly with the two lubricants. Furrows can be observed in the sliding direction on both wear scar micrographs, but the samples lubricated with Castor oil also exhibited some grooves. Additionally, wear track profiles revealed that there was abrasive wear that removed the material from the surface, and part of it was accumulated on the edges (pile up), generating deeper wear scars than those at $25{ }^{\circ} \mathrm{C}$ in the two lubricated systems.

The wear rate $(\mathrm{K})$ and volume loss $(\mathrm{V})$ of the disk samples obtained with Castor and Reference oil as lubricants at 25 and $70^{\circ} \mathrm{C}$ are depicted in Figure 7. Generally, it can be seen that the wear rate and volume loss values were higher at $70{ }^{\circ} \mathrm{C}$ than at $25^{\circ} \mathrm{C}$ for both lubricants. The lowest values of volume loss and wear rate were found under lubrication with Reference oil at the two temperatures, reaching values of $2.8 \times 10^{-4} \mathrm{~mm}^{3}$ and $5.5 \times 10^{-8} \mathrm{~mm}^{3} / \mathrm{Nm}$ at $25^{\circ} \mathrm{C}$, and of $1.2 \times 10^{-2} \mathrm{~mm}^{3}$ and $2.4 \times 10^{-6}$ $\mathrm{mm}^{3} / \mathrm{Nm}$ at $70{ }^{\circ} \mathrm{C}$, respectively. These values meant a reduction of $63 \%$ at $25^{\circ} \mathrm{C}$ and $81 \%$ at $70^{\circ} \mathrm{C}$ with respect to those obtained under Castor oil lubrication. Among other factors, the higher wear at $70{ }^{\circ} \mathrm{C}$ can be mainly attributed to the viscosity reduction of both oils; this indicates less lubricating films between the surfaces in contact. This can be related to the lower film thickness ratio obtained in the boundary lubrication (see Appendix A). 
Figure 8 shows the evaluation of Vickers Microhardness on the wear track surface of 4140 steel disks tested against WC and lubricated with Castor and Reference oil at two temperatures. After friction tests, the hardness of the material on the worn surface decreased in all systems. At $25^{\circ} \mathrm{C}$, the samples most affected regarding hardness were those lubricated with Castor Oil, which presented a hardness reduction of $6.5 \%$. Taking the previous results into account, the samples also exhibited minor friction coefficients. In that sense, to investigate the effects that friction had on the worn surface of the steel, the surfaces were chemically etched with Nital solution. As representative, in Figure 9, optical micrographs show the evidence of Vickers indentation within the wear surface (Figure 9a), as well as the presence of elongated ferrite in the direction of sliding (Figure 9b) on a sample tested with Castor oil lubrication at $70^{\circ} \mathrm{C}$. On the other hand, to corroborate and deepen the analysis of the microstructural change, the steel samples were cut transversely to analyze the affected area. The specimens were carefully polished to a mirror finish and etched with Nital solution. In Figure 10 a ferrite layer on the worn surface may be seen. This phenomenon could be due to the cooperative action of temperature and deformations on the contact surface. Ferrite is the softest and most ductile constituent of steel; for that reason, it can be concluded that the formation of a ferrite layer on the surface caused the hardness to decrease, consequently increasing wear.
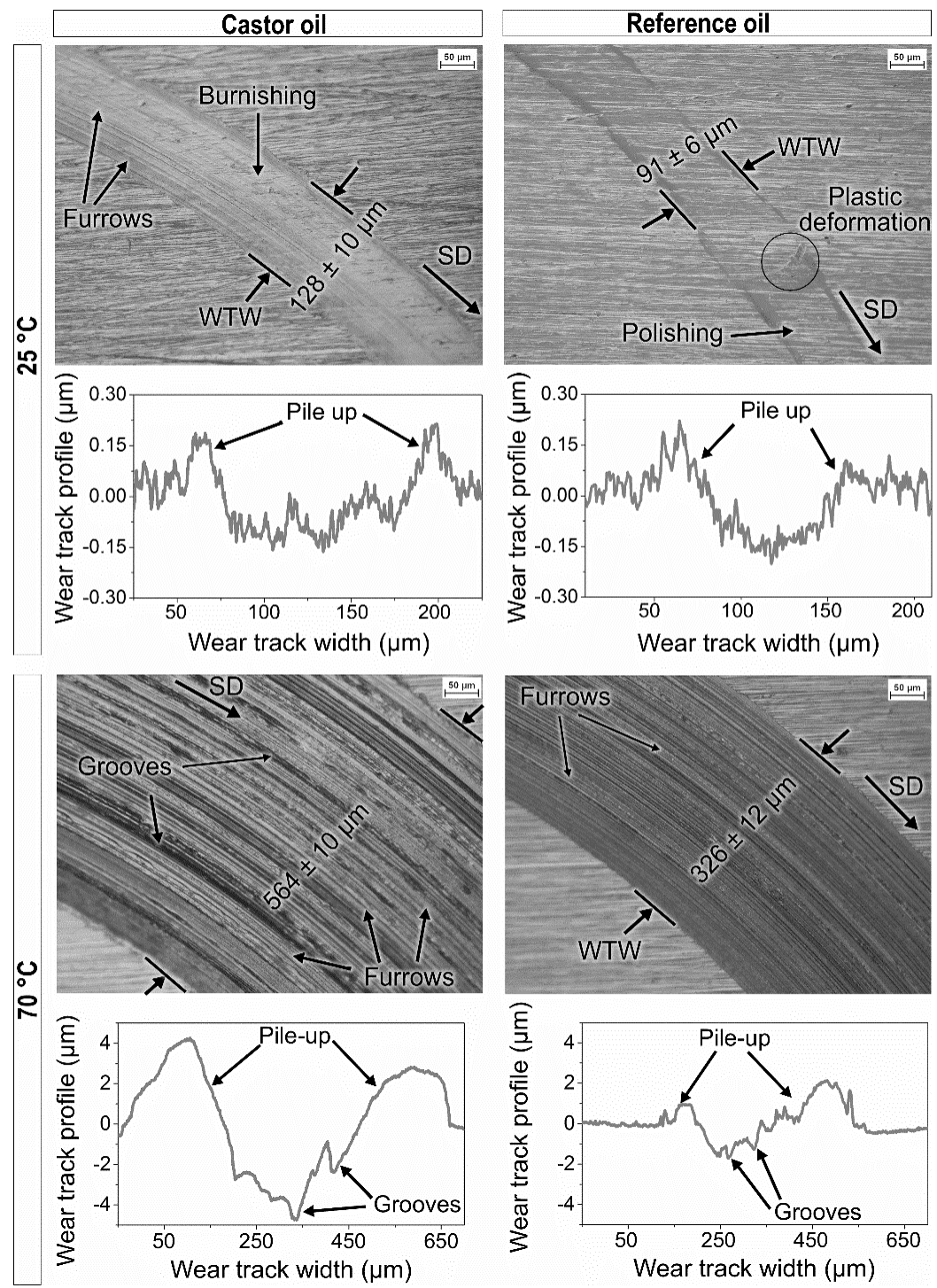

Figure 6. Optical micrographs at 200X of the wear track and wear track profiles on AISI 4140 vs. WC after friction tests lubricated with Castor and Reference oil at 25 and $70{ }^{\circ} \mathrm{C}$. SD: Sliding direction. 
The lubricating friction behavior of 4140 steel had been studied in other tribosystems, where lubricants of different natures had been employed, and the steel properties changed by heat treatments or using coatings to improve the tribological behavior of the steel. Çelik et al. [22] reported higher friction coefficients (from 0.095 to 0.122 ) in a system of hardened and tempered AISI 4140 steel and WC 6\% Co under lubrication with engine oil (SAE 10W) modified with nano hexagonal boron nitride nanoparticles at ambient temperature $\left(20^{\circ} \mathrm{C}\right)$. They also found higher wear rate values from $1.2 \times 10^{-6}$ to $5.2 \times 10^{-6} \mathrm{~mm}^{3} / \mathrm{Nm}$. Meanwhile, Rübig et al. [23] reported a tribosystem of AISI 4140 steel coated with DLC and 100Cr6 ball counterpart under lubricated conditions with synthetic oil (SAE $10 \mathrm{~W}-60)$ at ambient temperature $\left(22^{\circ} \mathrm{C}\right)$. Their results showed friction coefficients similar to the present work's results, from 0.05 to 0.08 , and wear rate values from approximately $1.71 \times 10^{-9}$ to $1.35 \times 10^{-6} \mathrm{~mm}^{3} / \mathrm{Nm}$. At higher temperatures, Dyson et al. [24], evaluated the friction behavior of AISI 4140 and Polyaryletherketones under lubrication with trinonyltrimellitate ester at temperatures from 150 to $170{ }^{\circ} \mathrm{C}$; they found higher friction coefficients, i.e., 0.06 to 0.12 . The friction coefficient and the wear rate of the AISI 4140 steel with Castor oil lubrication are similar- and even lower-than those obtained in similar tribosystems.

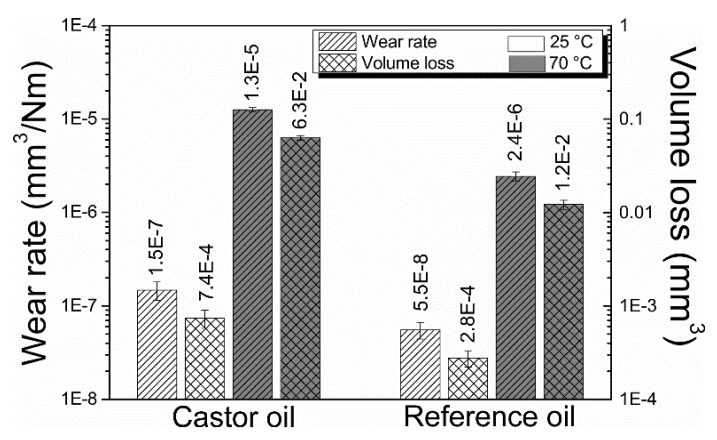

Figure 7. Wear rate and Volume loss of AISI 4140 vs. WC lubricated with Castor and Reference oil at 25 and $70{ }^{\circ} \mathrm{C}(Y$-axis in logarithmic scale).

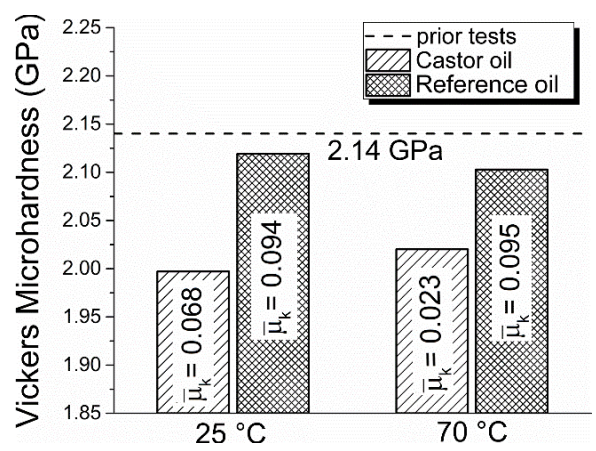

Figure 8. Evaluation of Vickers Microhardness on wear track surface of AISI 4140 tested against WC lubricated with Castor and Reference oil at 25 and $70^{\circ} \mathrm{C}$.
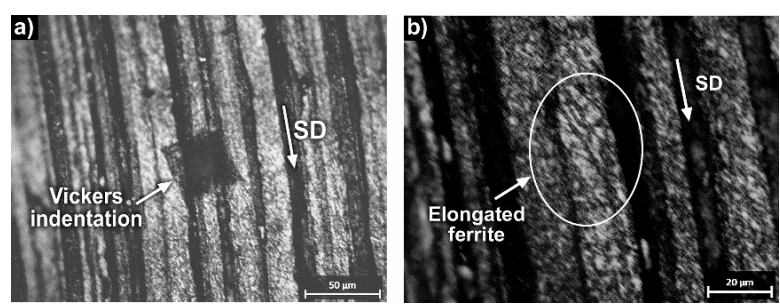

Figure 9. Worn surface lubricated with Castor oil at $70{ }^{\circ} \mathrm{C}$ : Vickers indentation (a) and microstructure of steel (b). 


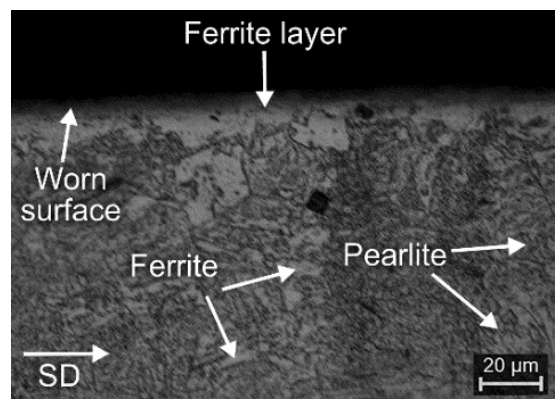

Figure 10. Microstructure of the steel in the cross-section after friction test lubricated with Castor oil at $70{ }^{\circ} \mathrm{C}$.

\subsection{Lubricant Degradation}

Figure 11 shows the evaluation of carbonyl band $(\mathrm{C}=\mathrm{O})$ of Castor (a) and Reference $(\mathrm{b})$ oil before and after tribological tests at 25 and $70{ }^{\circ} \mathrm{C}$. It can be appreciated that this band is characteristic of the two oils, and after the tribological test, this peak increased significantly. By measuring the peak area, there were observed increments of this band by $12 \%$ and $59 \%$ for Reference oil, and $18 \%$ and $53 \%$ for Castor Oil, at 25 and $70{ }^{\circ} \mathrm{C}$, respectively. This can be attributed to the oxidation breakdown of products in oils. These oxidation products change the lubricant properties so that the lubricating power decreases; this is reflected in lower lubricating films, and therefore, higher wear of the materials. It is important to mention that these values are lower than what can be expected in a real application, due to the present test duration and the controlled conditions. In fact, recently an evaluation of lubricant degradation by oxidation has been reported. In that study, an exponential increase in oxidation (by the analysis of carbonyl group) of different engine oils with service life [13] was reported. By analysis of the latter work, an increase in the carbonyl band of up to $900 \%$ for an engine mineral oil after $16,000 \mathrm{~km}$ (1333 $\mathrm{h}$ approximately) can be obtained.
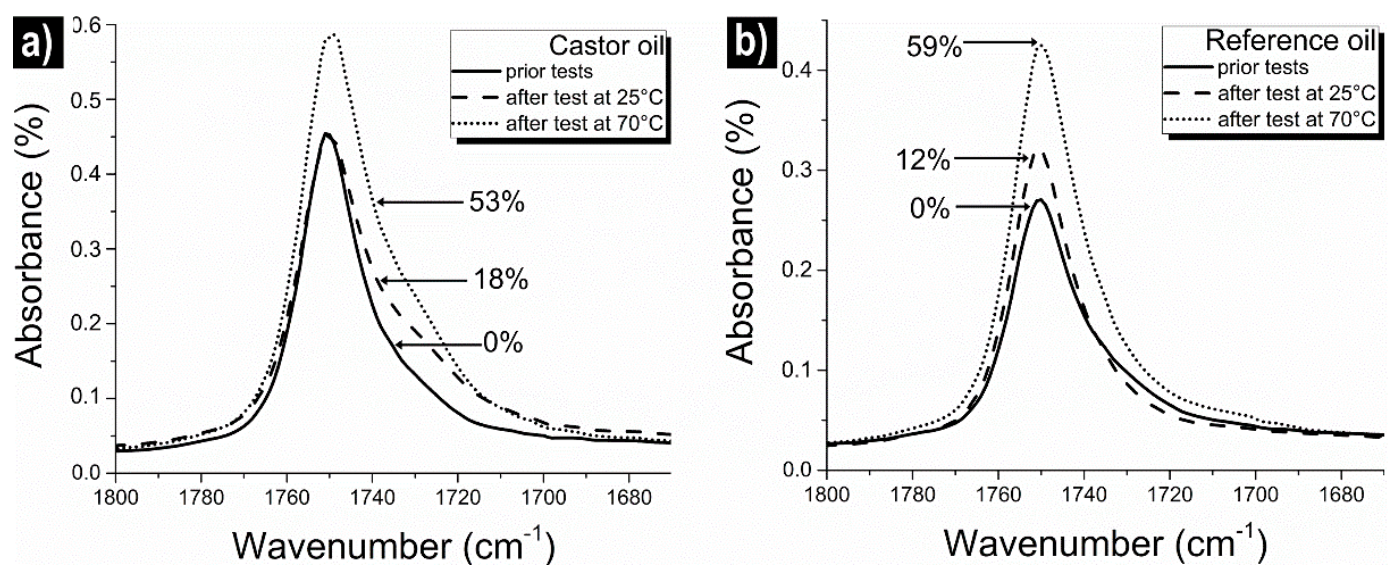

Figure 11. Evaluation of carbonyl band $(\mathrm{C}=\mathrm{O})$ of Castor (a) and Reference (b) oil before and after tribological tests at 25 and $70{ }^{\circ} \mathrm{C}$.

When an oil degrades by oxidation, the antioxidant additive first wastes away; then, the base oil oxidizes [14]. That could be why Reference oil underwent lower oxidative degradation at room temperature $\left(25^{\circ} \mathrm{C}\right)$ than Castor oil, which is pure (without any additive). Nevertheless, when the temperature rose to $70{ }^{\circ} \mathrm{C}$, the degradation of Reference oil was greater than that of Castor oil; This could mean that its base oil oxidizes faster than Castor oil. 


\section{Conclusions}

In this study, the use of biodegradable Castor oil as lubricant on the tribological performance of AISI 4140 steel vs. WC at temperatures of 25 and $70{ }^{\circ} \mathrm{C}$ was examined.

In general, Castor oil exhibited better friction and oxidation resistance at higher temperatures than a fully formulated commercial oil. However, it exhibited higher wear rate with respect to the reference oil. Despite this, these results suggest that Castor oil could be used as bio-lubricant in mechanical elements which are subjected to high friction.

The conclusions are as follow:

- The friction behavior of 4140 steel/WC with Castor Oil lubrication at the two temperatures was notably better than those obtained using Reference oil lubrication. There were reductions of $27 \%$ and $76 \%$ at 25 and $70{ }^{\circ} \mathrm{C}$, respectively.

- With the use of Castor oil as a lubricant, an increase in steel wear was observed compared to that generated under lubrication with Reference oil. The wear rate was up to an order of magnitude greater.

- A notable change in the microstructure of the steel was observed due to the friction process. A layer of ferrite (created on the surface as result of friction forces) could cause a reduction in hardness, consequently giving rise to greater wear of materials.

- Castor oil exhibited better oxidation resistance than the base of the reference oil.

Author Contributions: For the present work, M.T.H.-S. and L.D.A.-C. performed the experiments: friction, microhardness, metallography techniques, viscosity and FTIR measurements; and participated in the results analysis. M.T.H.-S. also collaborated with the writing-original draft preparation. J.E.B.-G. collaborated in the experimentation and analysis of the results of ${ }^{1} \mathrm{H}-\mathrm{NMR}$ spectroscopy. J.S.G.-M. supervised, validated the experimental results, and analyzed the general results. K.J.M. directed the research project, formulating research goals and aims, analyzed, and synthesized the results, and collaborated with the writing-review of the manuscript.

Funding: This research received no external funding.

Acknowledgments: The authors gratefully acknowledge Tecnológico Nacional de México (TecNM) for the financial support of this study (5724.16-P Grant); to Facultad de Química, Universidad de Guanajuato, Noria Alta S/N, 36050 Guanajuato, Guanajuato, México for NMR technical support.

Conflicts of Interest: The authors declare no conflict of interest.

\section{Appendix A}

\section{Lubrication Regime}

The primary objective of a lubricant is to separate the surfaces in contact by a thin film to reduce friction and wear. Depending of the thickness of that layer, the system will be affected by a specific lubrication mechanism which is defined by the lubrication regime. The lubrication regime can be boundary, mixed, or hydrodynamic/elastohydrodynamic (HD/EHD) lubrication [2,19]. The film thickness ratio (also known as lambda ratio), a relationship between minimum film thickness and the composite surface roughness, $\lambda=\mathrm{h}_{\min } / \sigma^{*}$, is a parameter with which the lubrication regime can be estimated. Generally, the systems work under boundary lubrication when lambda is less than 1, mixed lubrication when lambda is between 1 and 3, and HD/EHD lubrication for values of lambda greater than 3 . These values may vary among authors.

In an effort to determine the lubrication regimes in which the present systems will operate, the film thicknesses were calculated by the theory of Hamrock and Dowson [25]. According to them, the minimum lubricant film thickness is given by $h_{\min }=H_{\min } R_{x}$ where $H_{\min }$ is the dimensionless film thickness parameter and $R_{x}$ is the effective radius. The dimensionless film thickness parameter is defined by Equation (A1) where the dimensionless parameters of speed (U), material (G), load (W), and ellipticity (k) are defined by Equations (A2) to (A5), respectively. 


$$
\begin{gathered}
\mathrm{H}_{\min }=3.63 \mathrm{U}^{0.68} \mathrm{G}^{0.49} \mathrm{~W}^{-0.073}\left(1-e^{-0.68 \mathrm{k}}\right) \\
\mathrm{U}=\eta_{0} \mathrm{~V}_{\mathrm{r}} /\left(\mathrm{E}^{\prime} \mathrm{R}_{\mathrm{x}}\right) \\
\mathrm{G}=\mathrm{E}^{\prime} \alpha_{\mathrm{p}} \\
\mathrm{W}=\mathrm{F} /\left(\mathrm{E}^{\prime} \mathrm{R}_{\mathrm{x}}{ }^{2}\right) \\
\mathrm{k}=\mathrm{a} / \mathrm{b}
\end{gathered}
$$

In Equations (A2) to (A5), $\eta_{0}$ is the viscosity at atmospheric pressure of the lubricant at the temperature of interest, $\mathrm{V}_{\mathrm{r}}$ is the relative velocity of the disk, $\mathrm{E}^{\prime}$ is the effective elastic moduli of the system, $\alpha_{\mathrm{p}}$ is the pressure-viscosity coefficient at the same temperature, $\mathrm{F}$ is the normal load, and a and $\mathrm{b}$ are the semimajor and semiminor axes of the Hertzian contact ellipse. All these values are established or can be calculated from information in Section 2.4 except the pressure-viscosity coefficient $\left(\alpha_{\mathrm{p}}\right)$. This coefficient can be estimated by using direct or indirect methods. The direct method consists on the analysis of viscosity data of the lubricant of interest at several pressures, while indirect methods can be the analysis of lubricant film thickness data or by correlations based on the physical properties of the lubricant.

In this work, the pressure-viscosity coefficient $\left(\alpha_{\mathrm{p}}\right)$ was calculated by the method proposed by Johnston [26] by Equation (A6).

$$
\alpha_{\mathrm{p}}=-\beta\left(\mathrm{S}_{\mathrm{V} / \mathrm{T}}\right) / 2 \alpha_{\mathrm{T}} \mathrm{T}^{2}
$$

where $\beta$ is the coefficient of compressibility $\left(\mathrm{Pa}^{-1}\right), \mathrm{S}_{\mathrm{V} / \mathrm{T}}$ is slope of the straight line generated when graphing the natural logarithm of the viscosity at atmospheric pressure against the reciprocal of the temperature $(\mathrm{K}), \alpha_{\mathrm{T}}$ is the coefficient of thermal expansivity $\left(\mathrm{K}^{-1}\right)$, and $\mathrm{T}$ is the temperature in $\mathrm{K}$.

The pressure-viscosity coefficient values of the Castor and Reference oil as well as the parameters used for the calculation of these coefficients are listed in Table A1 for the two temperatures.

Table A1. Pressure-viscosity coefficient $\left(\alpha_{\mathrm{p}}\right)$ of Castor and Reference oil.

\begin{tabular}{|c|c|c|c|c|c|c|c|c|c|}
\hline Lubricant & $\begin{array}{c}\text { Temperature } \\
\left({ }^{\circ} \mathrm{C}\right)\end{array}$ & $\mathbf{U}$ & $\mathbf{W}$ & $\mathbf{k}$ & G & $\mathbf{H}_{\min }$ & $h_{\min }(\mu \mathrm{m})$ & $\lambda$ & $\begin{array}{c}\text { Lubrication } \\
\text { Regime }\end{array}$ \\
\hline \multirow{2}{*}{ Castor oil } & 25 & $4.62 \times 10^{-12}$ & $1.62 \times 10^{-6}$ & 1 & 5715 & $6.44 \times 10^{-6}$ & 0.019 & 0.39 & Boundary \\
\hline & 70 & $4.32 \times 10^{-13}$ & $1.62 \times 10^{-6}$ & 1 & 5046 & $1.21 \times 10^{-6}$ & 0.004 & 0.07 & Boundary \\
\hline \multirow{2}{*}{ Reference oil } & 25 & $8.55 \times 10^{-12}$ & $1.62 \times 10^{-6}$ & 1 & 7194 & $1.09 \times 10^{-5}$ & 0.033 & 0.66 & Boundary \\
\hline & 70 & $7.05 \times 10^{-13}$ & $1.62 \times 10^{-6}$ & 1 & 6372 & $1.89 \times 10^{-6}$ & 0.006 & 0.11 & Boundary \\
\hline
\end{tabular}

\begin{tabular}{cccccc}
\hline Lubricant & Temperature $\left(^{\circ} \mathbf{C}(\mathbf{K})\right)$ & $\beta_{\mathrm{T}}{ }^{\mathbf{a}}\left(\mathbf{P a}^{-\mathbf{1}}\right)$ & $\alpha_{\mathbf{T}}{ }^{\mathbf{b}}\left(\mathbf{K}^{-\mathbf{1}}\right)$ & $\mathbf{S}_{\mathbf{V} / \mathrm{T}}(\mathbf{K})$ & $\alpha_{\mathbf{p}}\left(\mathbf{P a}^{-\mathbf{1}}\right)$ \\
\hline \multirow{2}{*}{ Castor oil } & $25(298.15)$ & $4.20 \times 10^{-10}$ & \multirow{2}{*}{$-7.47 \times 10^{-4}$} & \multirow{2}{*}{5266} & $1.67 \times 10^{-8}$ \\
& $70(343.15)$ & $4.92 \times 10^{-10}$ & & & $1.47 \times 10^{-8}$ \\
\hline \multirow{2}{*}{ Reference oil } & $25(298.15)$ & $3.30 \times 10^{-10}$ & \multirow{2}{*}{5750} & $2.10 \times 10^{-8}$ \\
& $70(343.15)$ & $3.87 \times 10^{-10}$ & $-5.08 \times 10^{-4}$ & & $1.86 \times 10^{-8}$ \\
\hline
\end{tabular}

${ }^{\mathrm{a}}$ From FIG. 6 in Wright [27]. ${ }^{\mathrm{b}} \alpha \mathrm{T}=(1 / \rho)(\Delta \rho / \Delta \mathrm{T})$.

Once the pressure-viscosity coefficients were calculated, the minimum lubricant film thickness values and lubrication regime for Castor and Reference oil are as shown in Table A2.

Table A2. Estimation of Lubrication regime for Castor and Reference oil. 


\section{References}

1. Quinchia, L.A.; Delgado, M.A.; Reddyhoff, T.; Gallegos, C.; Spikes, H.A. Tribological studies of potential vegetable oil-based lubricants containing environmentally friendly viscosity modifiers. Tribol. Int. 2014, 69, 110-117. [CrossRef]

2. Menezes, P.L.; Reeves, C.J.; Lovell, M.R. Fundamentals of Lubrication. In Tribology for Scientists and Engineers, 1st ed.; Menezes, P.L., Ingole, S.P., Nosonovsky, M., Kailas, S.V., Lovell, M.R., Eds.; Springer: New York, NY, USA, 2013; pp. 295-336, ISBN 978-1-4614-1944-0.

3. Kabir, M.A.; Higgs, C.F.; Lovell, M.R. A Pin-on-Disk Experimental Study on a Green Particulate-Fluid Lubricant. J. Tribol. 2008, 130, 1-6. [CrossRef]

4. Sanchez, R.; Fiedler, M.; Kuhn, E.; Franco, J.M. Tribological characterization of green lubricating greases formulated with castor oil and different biogenic thickener agents: A comparative experimental study. Ind. Lubr. Tribol. 2011, 63, 446-452. [CrossRef]

5. Patel, V.R.; Dumancas, G.G.; Kasi Viswanath, L.C.; Maples, R.; Subong, B.J.J. Castor Oil: Properties, Uses, and Optimization of Processing Parameters in Commercial Production. Lipid Insights 2016, 9, 1-12. [CrossRef] [PubMed]

6. Perdomo, F.A.; Acosta-Osorio, A.A.; Herrera, G.; Vasco-Leal, J.F.; Mosquera-Artamonov, J.D.; Millan-Malo, B.; Rodriguez-Garcia, M.E. Physicochemical characterization of seven Mexican Ricinus communis L. seeds \& oil contents. Biomass Bioenergy 2013, 48, 17-24. [CrossRef]

7. Jain, A.K.; Suhane, A. Investigation of Tribological Characteristics of Non Edible Castor and Mahua Oils as Bio Lubricant for Maintenance Applications. In Proceedings of the 5th International \& 26th All India Manufacturing Technology, Design and Research Conference (AIMTDR 2014), Guwahati, Assam, India, 12-14 December 2014; Volume 416, pp. 1-6.

8. Madankar, C.S.; Pradhana, S.; Naika, S.N. Parametric study of reactive extraction of castor seed (Ricinus Communis L.) for methyl ester production and its potential use as bio lubricant. Ind. Crop. Prod. 2013, 43, 283-290. [CrossRef]

9. Hernández-Sierra, M.T.; Ortega-Álvarez, R.; Bravo-Sánchez, M.G.; Aguilera-Camacho, L.D.; García-Miranda, J.S.; Moreno, K.J. Tribological improvement of hardened and tempered AISI 4140 steel against $\mathrm{Al}_{2} \mathrm{O}_{3}$ by using bio-lubricant. MRS Adv. 2017, 2, 3873-3881. [CrossRef]

10. Zeng, Q.; Dong, G. Superlubricity behaviors of Nitinol 60 alloy under oil lubrication. Trans. Nonferr. Met. Soc. China 2014, 24, 354-359. [CrossRef]

11. Nagarajan, V.R.; Putatunda, S.K.; Boileau, J. Fatigue Crack Growth Behavior of Austempered AISI 4140 Steel with Dissolved Hydrogen. Metals 2017, 7, 466. [CrossRef]

12. Stachowiak, G.W.; Batchelor, A.W. Engineering Tribology, 4th ed.; Elsevier, Butterworth-Heinemann: Boston, MA, USA, 2013; pp. 51-68, ISBN 978-0-12-397047-3.

13. Macián, V.; Tormos, B.; Gómez, Y.A.; Salavert, J.M. Proposal of an FTIR Methodology to Monitor Oxidation Level in Used Engine Oils: Effects of Thermal Degradation and Fuel Dilution. Tribol. Trans. 2012, 55, 872-882. [CrossRef]

14. Al-Ghouti, M.A.; Al-Atoum, L. Virgin and recycled engine oil differentiation: A spectroscopic study. J. Environ. Manag. 2009, 90, 187-195. [CrossRef] [PubMed]

15. Socrates, G. Infrared and Raman Characteristic Group Frequencies: Tables and Charts, 3rd ed.; John Wiley \& Sons Ltd.: Chichester, UK, 2001; pp. 1-48, ISBN 0-470-09307-2.

16. Ahuja, D.; Kaushik, A. Castor oil-based polyurethane nanocomposites reinforced with organically modified clay: Synthesis and characterization. J. Elastom. Plast. 2016, 49, 315-331. [CrossRef]

17. Ducrocq, P.; Duquesne, S.; Magnet, S.; Bourbigot, S.; Delobel, R. Interactions between chlorinated paraffins and melamine in intumescent paint-Investing a way to suppress chlorinated paraffins from the formulations. Prog. Org. Coat. 2006, 57, 430-438. [CrossRef]

18. Zhang, J.; Tan, A.; Spikes, H. Effect of base oil structure on elastohydrodynamic friction. Tribol. Lett. 2017, 65, 1-24. [CrossRef]

19. Hamrock, B.J.; Schmid, S.R.; Jacobson, B.O. Fundamental of Fluid Film Lubrication, 2nd ed.; Marcel Dekker, Inc.: New York, NY, USA, 2004; ISBN 0-8247-5371-2. 
20. Edward, J.C. A Review of Applications of NMR Spectroscopy in the Petroleum Industry. In Spectroscopic Analysis of Petroleum Products and Lubricants; Nadkarni, R.A., Ed.; ASTM International: West Conshohocken, PA, USA, 2011; pp. 423-443, ISBN 978-0-8031-7020-9.

21. Lachenmeier, D.W.; Mildau, G.; Rullmann, A.; Marx, G.; Walch, S.G.; Hartwig, A.; Kuballa, T. Evaluation of mineral oil saturated hydrocarbons $(\mathrm{MOSH})$ and mineral oil aromatic hydrocarbons $(\mathrm{MOAH})$ in pure mineral hydrocarbon-based cosmetics and cosmetic raw materials using ${ }^{1} \mathrm{H}$ NMR spectroscopy [version 1 ; referees: 2 approved, 1 approved with reservations]. F1000Research 2017, 6. [CrossRef]

22. Çelik, O.N.; Ay, N.; Göncü, Y. Effect of Nano Hexagonal Boron Nitride Lubricant Additives on the Friction and Wear Properties of AISI 4140 Steel. Part. Sci. Technol. 2013, 31, 501-506. [CrossRef]

23. Rübig, B.; Heim, D.; Forsich, C.; Dipolt, C.; Mueller, T.; Gebeshuber, A.; Kullmer, R.; Holecek, R.; Lugmair, C.; Krawinkler, M.; et al. Tribological behavior of thick DLC coatings under lubricated conditions. Surf. Coat. Technol. 2017, 314, 13-17. [CrossRef]

24. Dyson, C.J.; Priest, M.; Fox, M.F.; Hopkins, B. The tribological behaviour of carbon fibre reinforced polyaryletherketones (PAEKs) through their glass transitions. Proc. Insit. Mech. Eng. Part J J. Eng. Tribol. 2015, 230, 1183-1196. [CrossRef]

25. Hamrock, B.J.; Dowson, D. Isothermal Elastohydrodynamic Lubrication of Point Contacts: Part 111-Fully Flooded Results. J. Lubr. Technol. 1977, 99, 264-275. [CrossRef]

26. Johnston, W.G. A Method to Calculate the Pressure-Viscosity Coefficient from Bulk Properties of Lubricants. ASLE Trans. 1981, 24, 232-238. [CrossRef]

27. Wright, W.A. Prediction of Bulk Moduli and Pressure-Volume-Temperature Data for Petroleum Oils. ASLE Trans. 1967, 10, 349-356. [CrossRef]

(C) 2018 by the authors. Licensee MDPI, Basel, Switzerland. This article is an open access article distributed under the terms and conditions of the Creative Commons Attribution (CC BY) license (http:/ / creativecommons.org/licenses/by/4.0/). 